\title{
Urban Ruralization and Its Impact On the Residential Environment of the City of Al-Qaim
}

\author{
Ahmed Mahmood Ali, Salah Othman Abed* \\ Directorate of Education, Ministry of Education, Anbar, Iraq \\ * dr.salah.alani@gmail.com
}

\begin{abstract}
KEYWORDS: $\quad$ Urbanization, Citification, Ruralization, Residential Environment, Traditions.
\end{abstract}
\begin{abstract}
:
The research has a more important and important study of the Iraqi cities in general and the cities of Anbar in particular, through field study and investigation in order to know the reasons that contribute directly or indirectly to the prevalence of this phenomenon, as it is affecting the quality of urban life and the nature of the urban texture of the city، By asking questions to the community sample about the behaviors of the existing city community, and focusing on the most prominent customs and traditions that the residents brought through the move of their place of residence from the countryside to the city, and it has been inherited from the life of the countryside, since significant numbers of the city's residents have rural origins, Where the city of Al-Qaim was distinguished by the area expansion and population size resulting from several factors, whether the natural increase of the population or through migration from the neighboring countryside or through the process of urban integration represented by the integration of the Karbala region of rural nature within the basic design of the city of Al-Qaim.
\end{abstract}




\title{
الترييف الحضري وأثره في البيئة السكنية لمدينة القائم
}

\author{
م.د. أحمد محمود علي، م.د. صلاح عثمان عبد* مبر \\ مدير ية تربية الأنبار، وزارة التربية، الأنبار، العراق \\ *dr.salah.alani@gmail.com
}

التحضر، التمدن، الترييف، البيئة السكنية، التقاليد.

الكلمات المفتاحية

Crossref d

https://doi.org/10.51345/.v32i2.358.g223

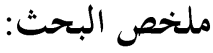

تناول البحث دراسة أهم وأبرز مشكلة تعالي منها المدن العراقية بشكل عام ومدن محافظة الانبار بشكل خحاص، من خلال

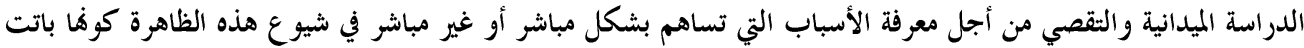

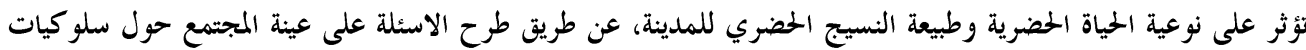

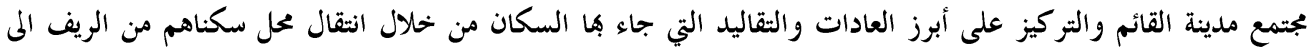

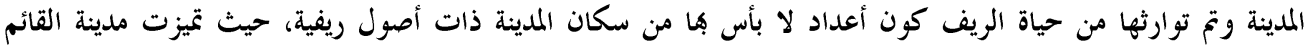

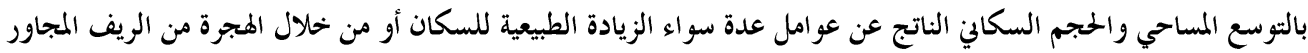

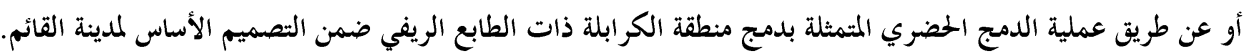

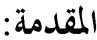

تعد ظاهرة الترييف الحضري من الظواهر اللافتة للنظر في العديد من المدن لاسيما المدن الكبرى التي تمتاز بارتفاع معدلات نموها السكاني يقابله التوسع في النمو العمرائ على حساب المناطق المجاورة، فضلا عن الهجرات الداخلية لاسيما من الارياف وما ينتج عنه من نقل عادات وتقاليد تلك المناطق الى المدن وهذا ما بنحه بشكل واضح في الدول النامية و الدول العربية، اذ اصبحت هذه المشكلة من ابرز المشاكل التي تعاني منها مدننا اذ اثرت على مظاهر التمدن من خحلال زيادة الضغط على المرافق والخدمات العامة، ونلاحظ هذه الظاهرة في مدينة حصيبة مركز قضاء القائم لا سيما بعد الاحداث الامنية التي مرت على العراق بعد عام 2003، فضلا عن الاحداث الامنية الاخيرة عام 2014.

مشكلة البحث: تتلخص مشكلة بالحث بالأسئلة الاتية:

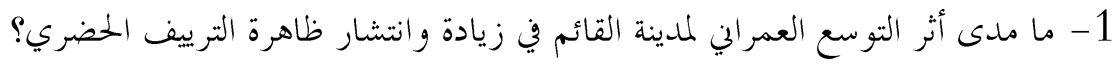


2- هل للهجرات الداخلية لسكان الارياف الى ملدينة القائم اثار سلبية في انتشار ظاهرة الترييف

$$
\text { الخضري؟ }
$$

3- هل لظاهرة الترييف الحضري اثارا سلبية على سكان مدينة القائم فيما يتعلق بتغيير سلوكهم

$$
\text { ونمط معيشتهم والتأثير على اساليب حياهم من جهة أخرى؟ }
$$

فرضية البحث: لظاهرة الترييف الحضري اثارا سلبية على طبيعة الحياة لمدنية القائم من خلال ثأثيرها

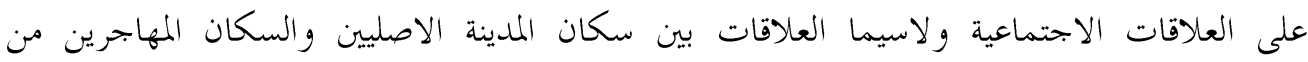
الارياف، فضلا عن مزاحمة سكان المدينة على الحخدمات والمرافق العامة المقدمة لهم. هدف البحث: يهاف البحث للكشف عن اهم الاثار السلبية التي خلفتها ظاهر الترييف الحضري داخل مدينة القائم والسعي لايجاد الحلول المناسبة للتخلص او التقليل على الاقل من هذه الاثار السلبية من خلال معالجة اهم الاسباب التي دفعت سكان الارياف الم الهجرة للمدينة، وبالتالي اعادة النسيج العمر اني والعلاقات الاجتماعية للمدينة عن طريق التخطيط العلمي لمواجهة هذه التحديات.

اولاً: مفاهيم عامة:

التمدن: هي مؤشر لتطور المجتمع واستثمار كافة الامكانات من أجل تحقيق أعلى درجات

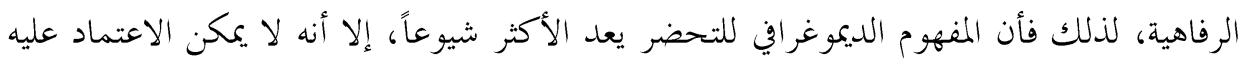
بتحديد تعريف معين للتحضر بسبب كون نمو المدن لا يعد مؤشر دال على ارتفاع مستوى (1) التحضر الترييف: هو أحد المظاهر التي باتت تنتشر في الوسط الحضري لأغلب المدن والمتمثلة بنقل ثقافات وممارسات وسلوكيات الريف الى المجتمعات الحضرية، فبعض هذه العادات و الثقافات الريفية تمتلك القدرة على الصمود أمام المؤثرات الحضرية، وبعضها عبارة عن سلو كيات انتشرت داخل

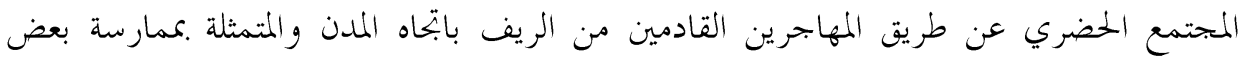

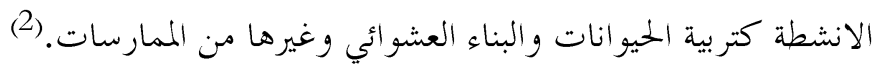

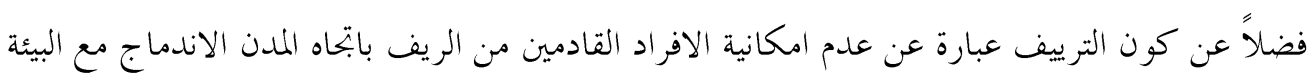

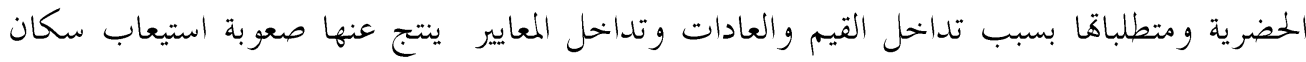
الريف لطبيع الحياة الحضرية(3). 
يلاحظ من خحلال تحليل خارطة رقم (1) إن مدينة القائم تقع على الضفة اليمنى لنهر الفرات في منطقة تقع عند نقطة الالتقاء بين بيئتين مختلفتين تتمثل الأولى بالبيئة الزراعية والاستقرار الريفي.

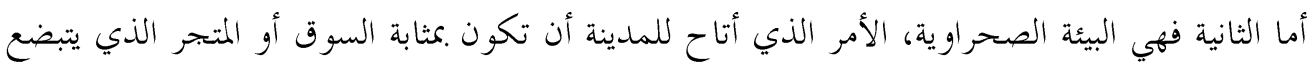

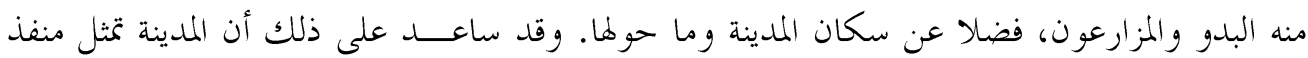

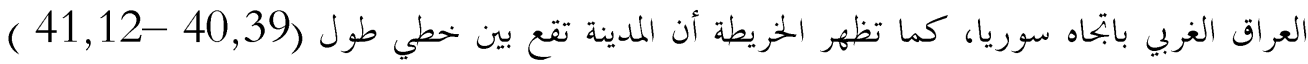

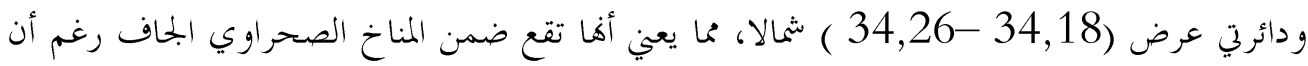

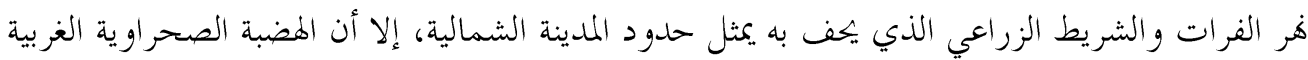

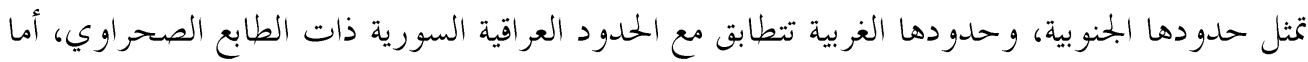
حدودها الشرقية متمثلة بقرية سعده، وهي بذلك تمثل مدينة هرية مدخحليه تلتحم عندها الأقاليم الطبيعية

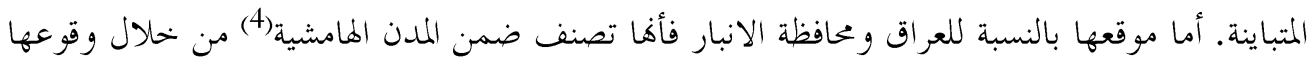
في طرف العراق والمحافظة الغربي باتجاه سوريا. خر يطة رقم (1) موقع مدينة القائم بالنسبة للعر اق ومحافظة الانبار

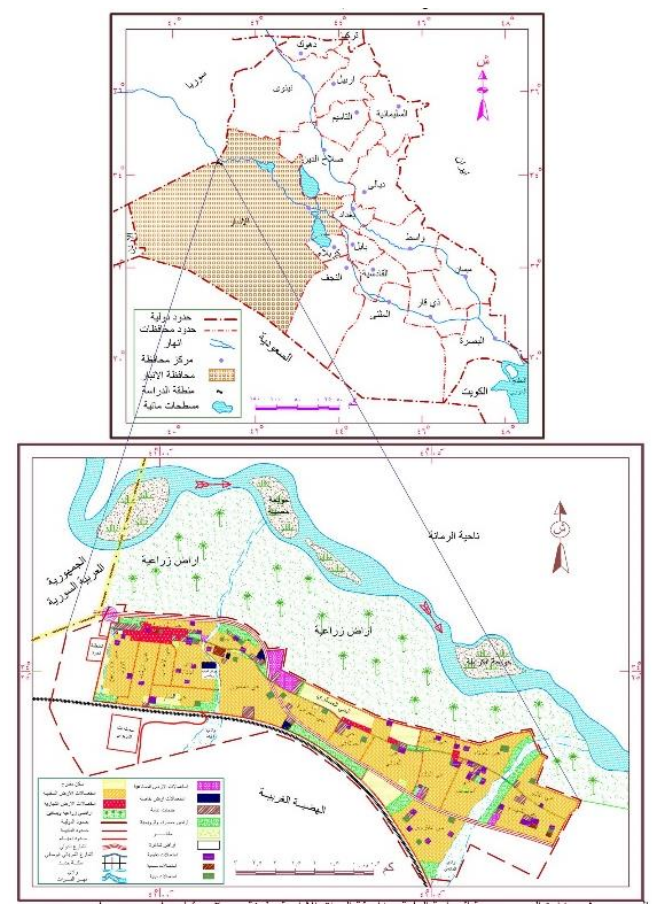

المصدر: 1- وزارة الاشغال والبلديات، مديرية التخطيط العمراني والتصميم الاساس لمدينة القائم، 1996،مقياس الرسم 5000/1.

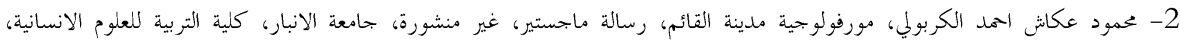
.42ص2011 
ثالثاً: مقومات نشوء ظاهرة الترييف الحضري في مدينة القائم -1 - التطور الاداري لمدينة القائم:

تعد مدينة القائم من المدن العراقية ذات البعد التأريخي والتي حضيت بموقع جغرافي متميز ساهم في توفير جميع مقومات الاستقرار، حيث استقر السكان على شكل تجمعات صغيرة، وان هذه هنه التجمعات السكانية في الماضي تطورت عبر الزمن إلى بتمعات كبرت شيئا فشيئا حتى رسمت الصورة الأولى للتوزيع المكاني للسكان، وقد تمثلت بقرية حصيبة الشمالية الواقعة على الضفة الجنوبية لنهر الفرات شمال ملدينة القائم حالياً و المتمثلة بالمنطقة الحدودية مع سوريا بالاضافة الى موضع مستقرة القائم التي تطورت بمرور

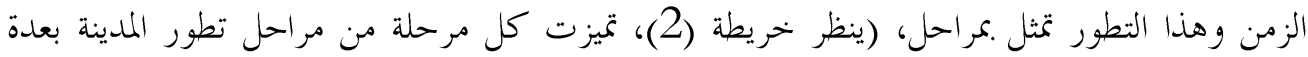
صفات تميزها عن المرحلة التي سبقتها.

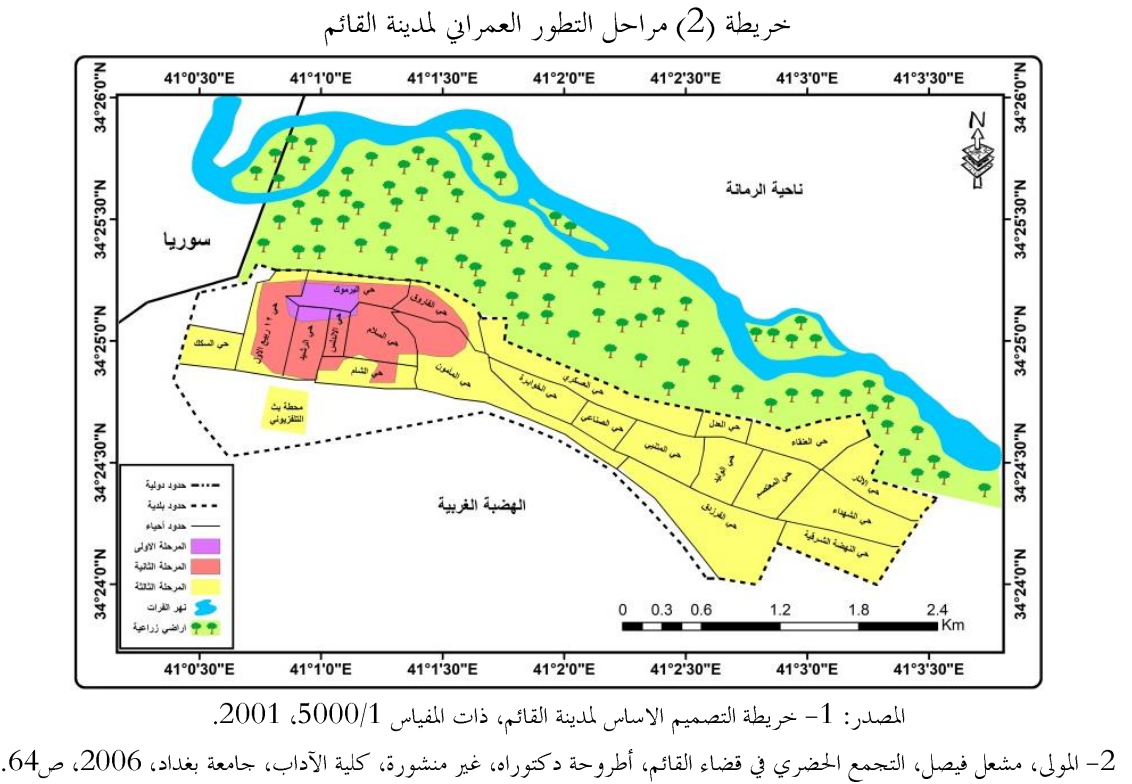

تمثلت المرحلة الاولى والممتدة من عام (1100ق.م ـ 1970م) (4) بظهور أولى بوادر الاستقرار حتى وصلت مساحة المدينة انذاك ما يقارب من (332.4) هكتار، وقد اكتسبت المدينة خلال هذه المرحلة الصفة الادارية كناحية تابعة لقضاء عنه(5)، وفق المرسوم الملكي الصادر عام 1935 و.بما ان المعيار

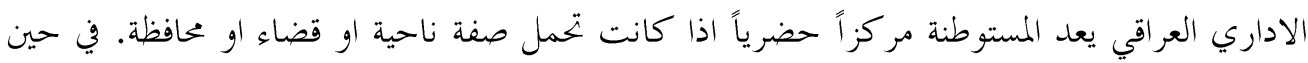
امتدت المرحلة الثانية من عام (1971 ـ 1990) والتي شغلت مساحة تقدر بــ(391.7) هكتار 
وقد شهدت المدينة خلال هذه المرحلة صدور المرسوم الجمهوري المرقم (1163) عام 1968) المقتضي استحداث قضاء القائم ويكون مركزه مدينة القائم ويضم ثلاث نواحي (العبيدي، الكرابلة، والرمانة)، وخلال هذه المرحلة بدأت المنطقة تشهد توجهات تنموية تمثلت ببناء اقطاب نمو صناعية

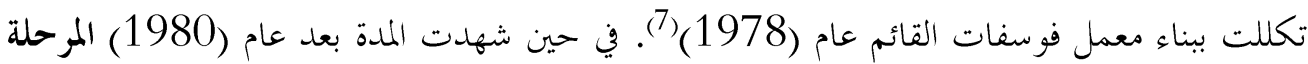

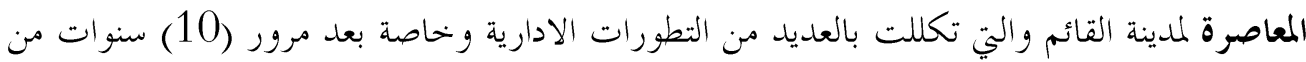

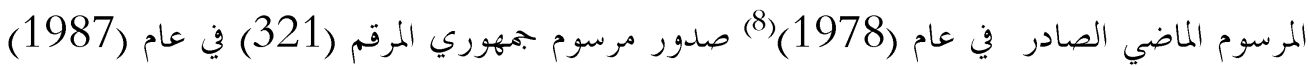
القاضي بانتزاع الصفة الادارية عن ناحية الكرابلة واعتبارها قصبة ريفية تابعة لقضاء القائم ليصبح المركز الحضري ها من ضمن التصميم الاساس لمدينة القائم مما يسمى بعملية الدمج الحضري لتصبح من ضمن احياء المدينة وباتت مساحة المدينة تشغل (1623,5) هكتار، محققا زيادة مطلقة عن المرحلة السابقة بلغت $(1231,8)$ هكتار وهذه الزيادة تعادل ما يزيد على ثناثة إضعاف مساحة المدينة في المرحلة

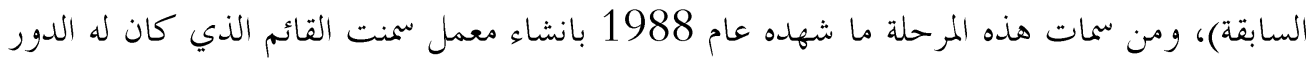
الواضح في تشغيل بحاميع من سكان القضاء، فضلاً عن ذلك فقد شهد عام 1995 تحسن للعلاقات (العر اقية ـ السورية) التي تكللت بفتح المعبر الحدودي بين البلدين المتمثل .كعبر القائم الذي ساهم في

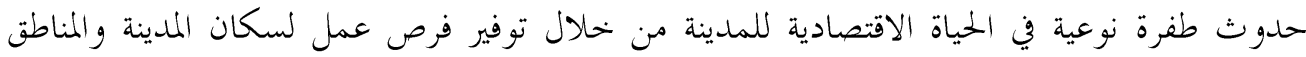
المجاورة، وبعد عام 2012 تم صدور قرار حكومي يقتضي استحداث ناحية الكرابلة من جديد لتهيد لتكون وحدة ادارية مستقلة تابعة لقضاء القائم، وخحلال هذا التطور الذي شهدته المدينة نلتمس بعض المقومات التي ساعدت في خلق ظاهرة الترييف الحضري من خلال انتقال بعض سلو كيات وانشطة الريف الى

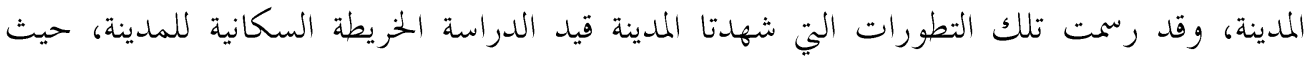
ركزت هذه الدراسة على مدينة حصيبة مركز مدينة القائم والمتمثلة حدودها بالمرحلة الثانية من عمر فئية

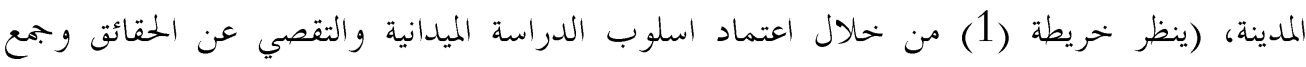
المعلومات بالاستبيان و الزيارات الميدانية للمدينة.

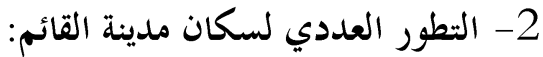
من خلال البيانات الرقمية للجدول (1) تبين أن سكان مدينة القائم في زيادة مستمرة وقد سجل قفزات كبيرة ومستمرة نتيجة للاسباب الطبيعية المتمثلة بكثرة الولادات او نتيجة لهجرة سكان الريف والمناطق

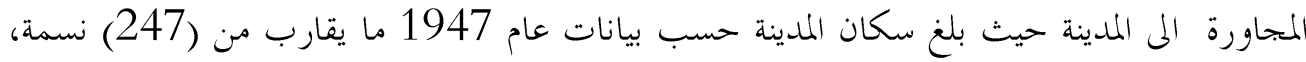

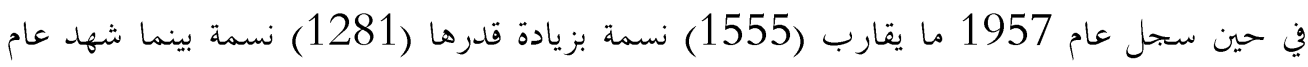


1965 زيادة مقدارها ( 1659) نسمة ليصبح العدد الكلي لسكان المدينة في العام ذاته (3214)

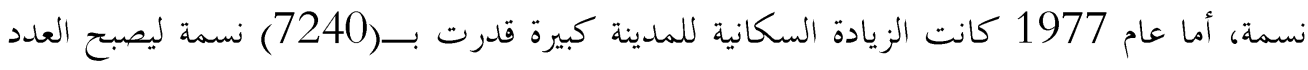

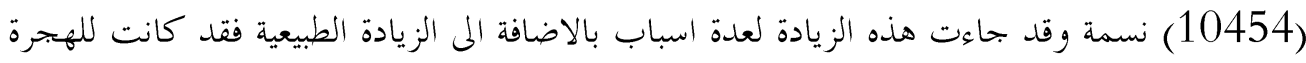

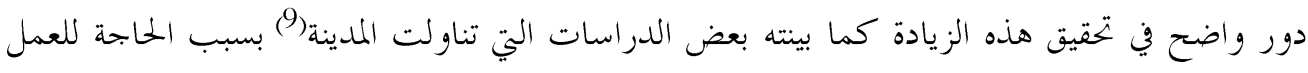

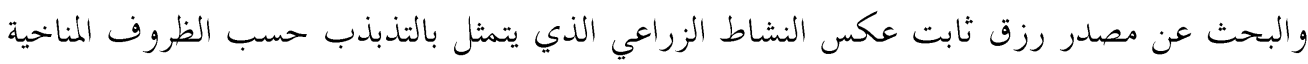

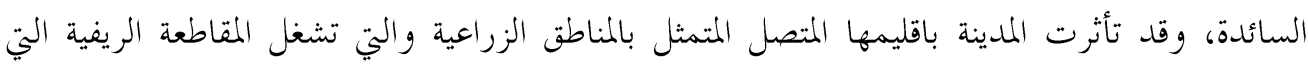

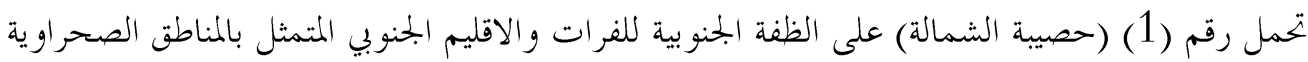

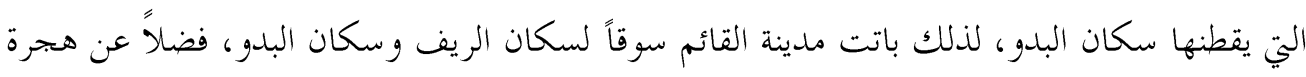

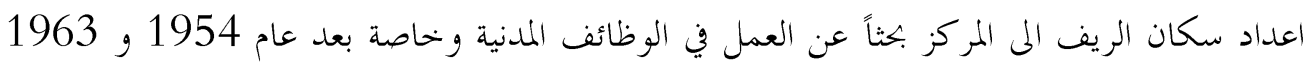

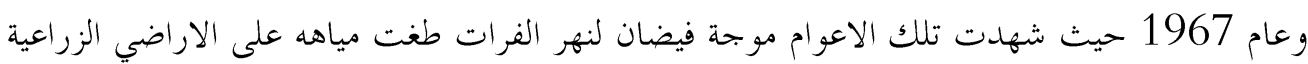

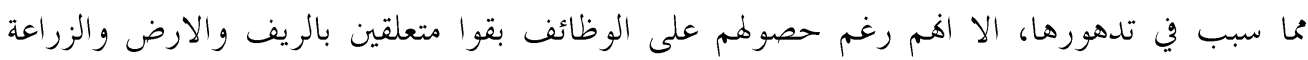

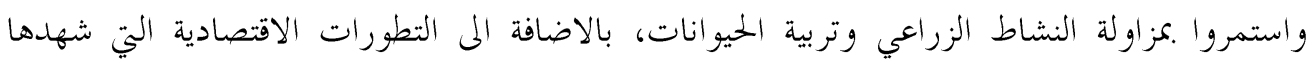

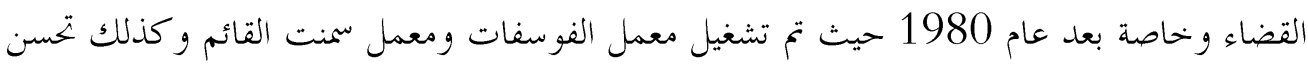

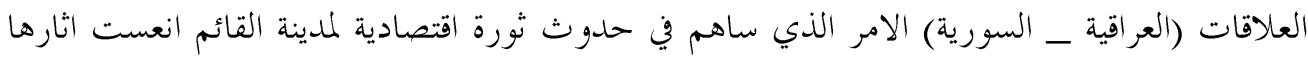

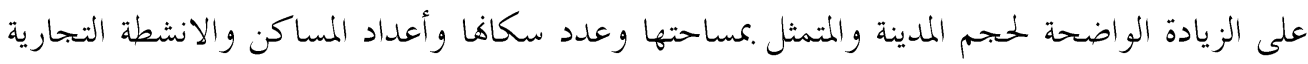

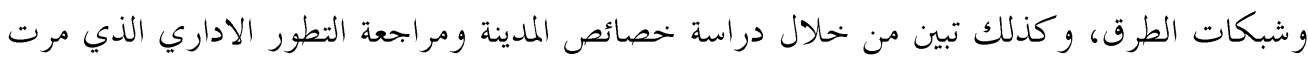

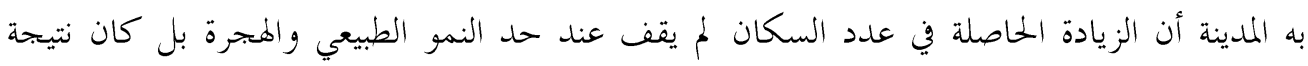

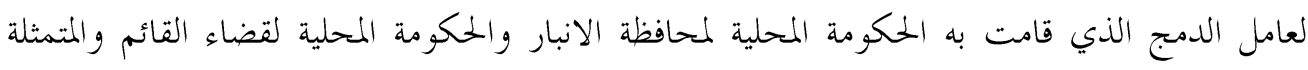

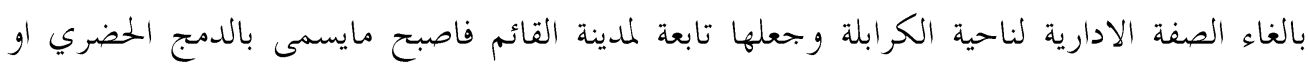

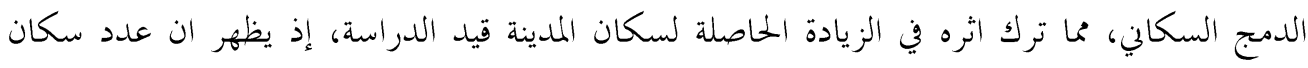

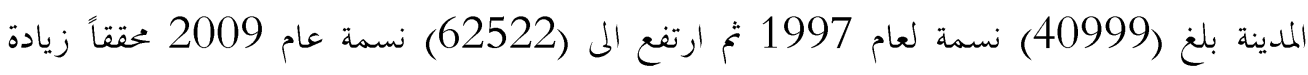

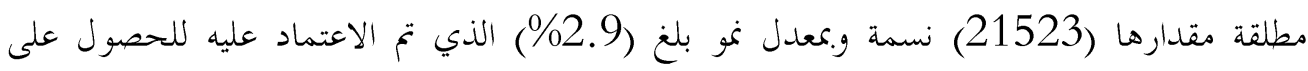

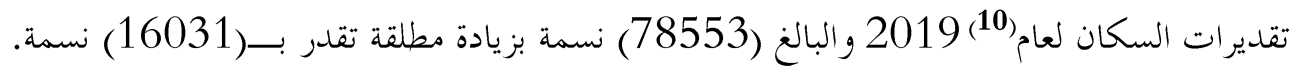


جدول رقم (1) التطور العددي لسكان مدينة القائم الفترة (1947-2019)

\begin{tabular}{|c|c|c|}
\hline مقدار الزيادة & عدد السكان & السنو ات \\
\hline & 274 & 1947 \\
\hline 1281 & 1555 & 1957 \\
\hline 1659 & 3214 & 1965 \\
\hline 7240 & 10454 & 1977 \\
\hline 7074 & 17528 & 1987 \\
\hline 23471 & 40999 & 1997 \\
\hline 21523 & 62522 & 2009 \\
\hline \multirow[t]{2}{*}{16031} & 78553 & 2019 \\
\hline & 215099 & المجموع \\
\hline
\end{tabular}

المصدر: 1- محمود عكاش احمد الكربولي، مورفولوجية مدينة القائم، رسالة ماجستير، غير منشورة، كلية التربية للعلوم الانسانية، جامعة الانبار، 2011، جداول 8، 81 .

2-التقدير ات السكانية بالاعتماد على معدل النمو للحصول على عدد السكان لعام 2019.

\section{3- 3ملية الدمج الحضري.}

اشار الباحث مكتزي بان المدن الكبرى تكونت نتيجة اندماج بحموعة من النوى مع بعضها البعض، فمدينة القائم ظهرت نتيجة للقرار السياسي كنواة أولى لبناء مدينة حدودية تنظم العلاقات التجارية بين

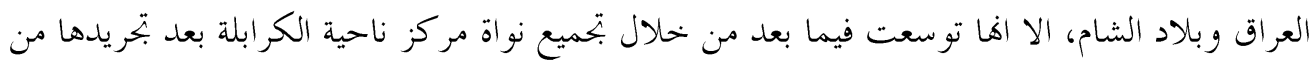

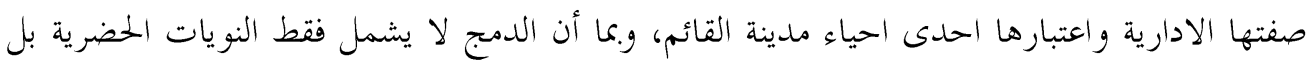

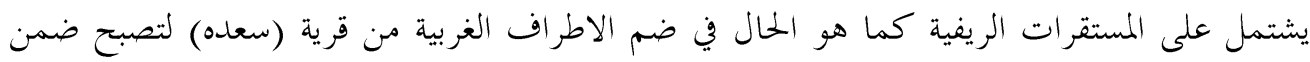

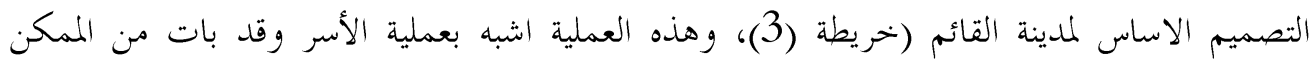
تسميتها بعملية الاسر الحضري(11). لذلك فان عملية الاسر الخضري تعتمد على مبدأ الضم الاجباري للمسقرات الريفية داخل المركب الحضري لتصبح في تعداد لاحق ضمن سكان الخضر علماً أنه لم يحدث أي تغير في نمط حياتم وطبيعة

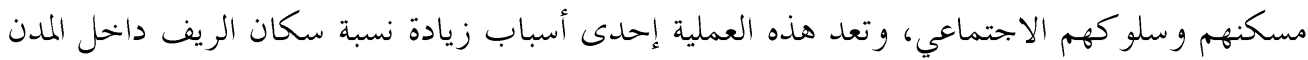
وبالتالي زيادة اسباب ظاهرة الترييف الحضري. 
خريطة رقم (3) التصميم الاساس لمدينة القائم خلال عملية دمج الكرابلة ضمن الحمدود الادارية لمدينة القائم

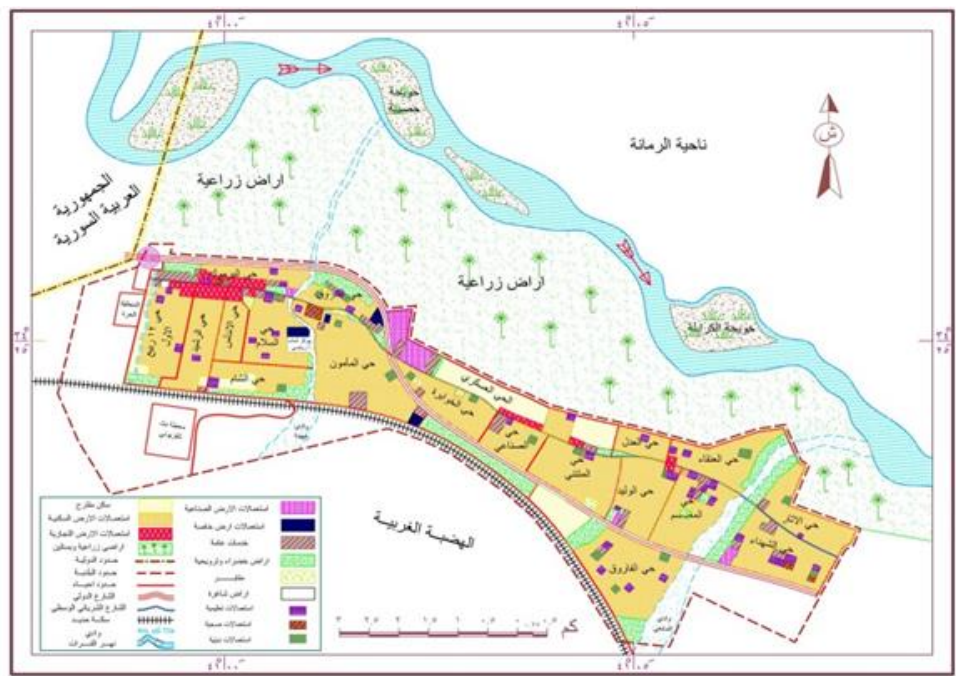

المصدر / عمود عكاش احمد الكربولي، مورفولو جية مدينة القائم، رسالة ماجستير، غير منشورة، كلية التربية للعلوم الانسانية، جامعة الانبار، 2011، ص141

وهذ ما يؤكده الجحدول (2) حيث نلاحظ أن أعداد السكان العاملين في الزراعة في زيادة مستمرة مع مراحل تطور المدينة، حيث بلغ العدد في عام 1997 (3272) مزارع يسكن في مدينة القائم، بينما كان العدد قبل عملية الدمج اي في عام 1978 ما يقارب من (652) مزارع مارع من سكنة مدينة القائم. وهذا ما يؤ كد من وجود أبرز عوامل ظهور مشكلة الترييف الخضري في المدينة.

رابعاً: مظاهر الترييف الحضري في مدينة القائم: 1- أحياء سكنية تتمتع بروابط عشائرية وريفية:

إن وجود مثل هذه الأحياء داخل الحيز الحضري للمدن يعد مظهراً وسبباً لإنتشار بعض السلو كيات

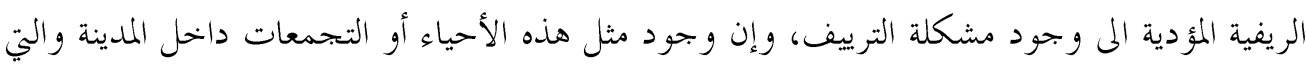

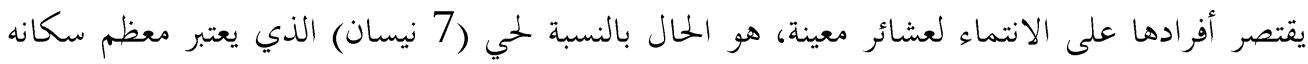

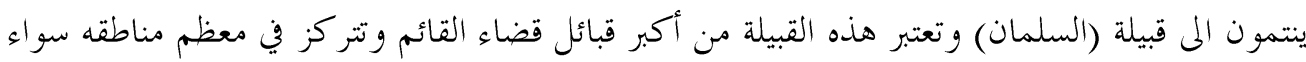

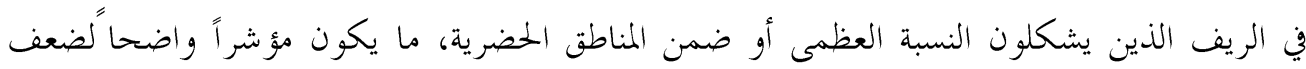
لاندماج في محيط المدينة الحضري. وعادةً ما تنشأ مثل هذه الأحياء كنتيجة لهجرة جماعية غير منظمة. 


\begin{tabular}{|c|c|}
\hline عدد المزارعين & السنة \\
\hline 156 & 1965 \\
\hline 652 & 1978 \\
\hline 3272 & 1997 \\
\hline
\end{tabular}

المصدر / عمود عكاش احمد الكربولي، مورفولوجية مدينة القائم، رسالة ماجستير، غير منشورة، كلية التربية للعلوم الانسانية، جامعة الانبار، 2011،ص136.

\section{2- 2 طبيعة ونمط الحياة الاجتماعية للأسرة:}

عدد العوائل في الوحدة السكنية: تعد ظاهرة تعدد الأسر في المسكن الو احد من أبرز مظاهر الريف لأها تعكس الطابع الاجتماعي والعشائري المتماسك للسكان لان الأسر ترغب بز يادة عدد أفرادها والسكن بشكل مشترك ليس على مستوى الأسرة المكونة من الأب وألام

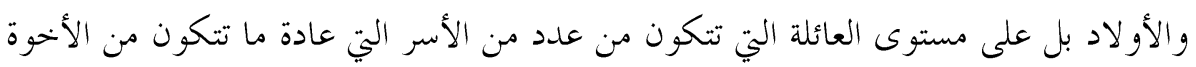

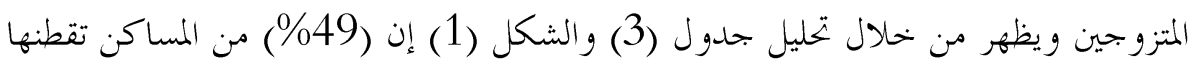

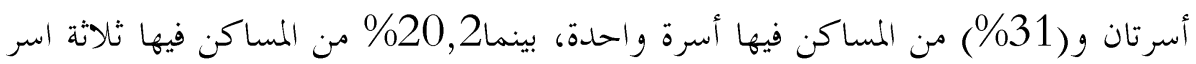

$$
\text { أو أكثر. }
$$

جدول رقم (3) طبيعة ونمط الحياة الاجتماعية للأسرة ضمن الحيز الحضري لمدينة القائم

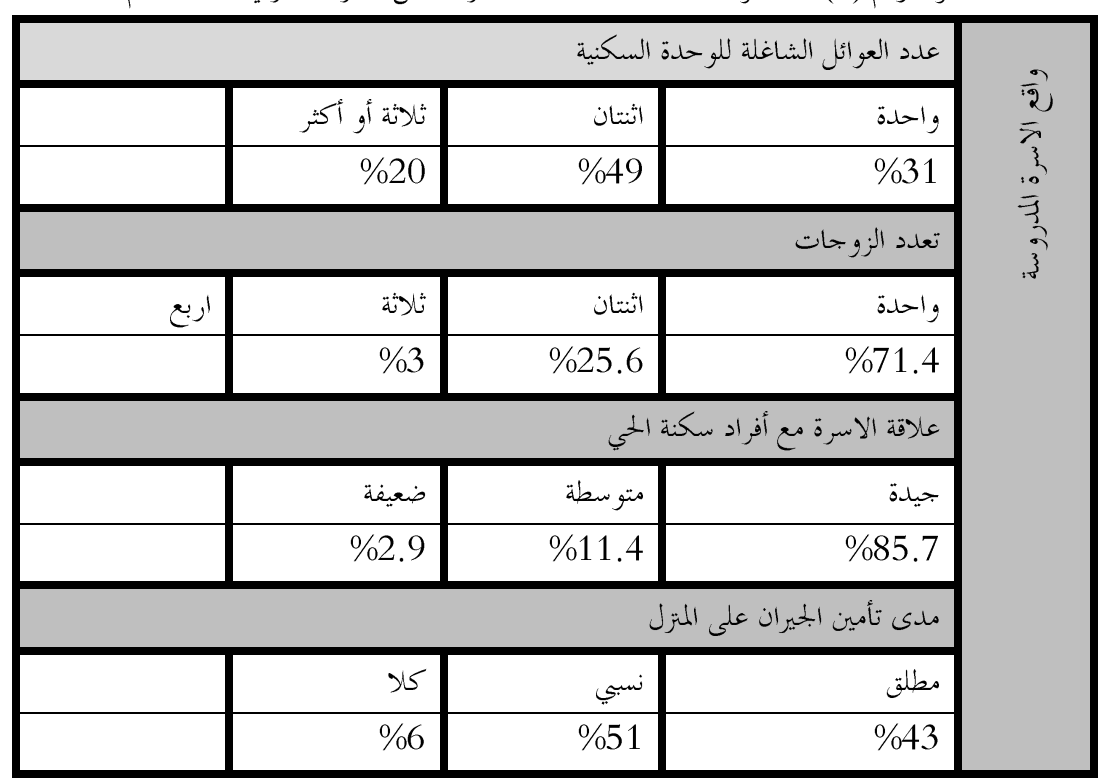


شكل رقم (1) طبيعة ونمط الحياة الاجتماعية للأسرة ضمن الحيز الحضري لمدينة القائم

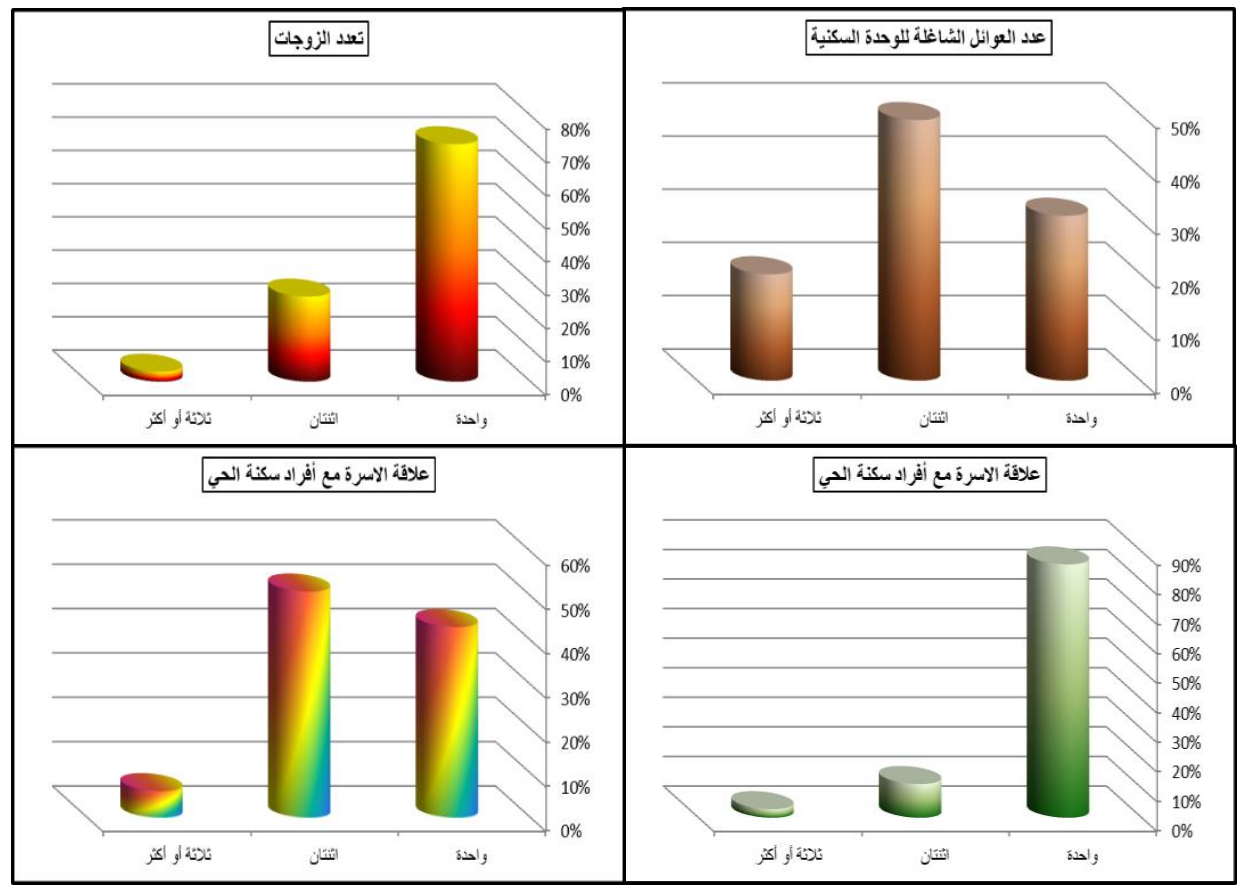

المصدر / بالاعتماد على بيانات جدول (3).

تعدد الزوجات: يعد سكان الريف من أكثر المجتمعات التي تؤمن بظاهرة تعدد الزوجات وهذا ناتج عن أسباب عدة، منها مايتعلق بزيادة الأيدي العاملة في الزراعة، على اعتبار أن العمل في زراعة المحاصيل الزراعية وتربية الحيوانات يحتاج الى عدد أكثر من العاملين، فضلاً عن العادات والتقاليد المتوارثة التي تسمح وتشجع على التعدد في الزوجات، لاشك أن هذه الظاهرة بدأت تنتقل الم المدن ومنها مدينة القائم التي يعد قسم من سكاها جاؤوا من الريف، لذلك يشير الجلدول (3) على أن ما يقارب من (28.6\%) من محتمع الدراسة يؤيدون ظاهرة تعدد الزوجات وفق اعتبارات اجتماعية ودينية واقتصادية. طبيعة العلاقة الاسرية مع افراد الحي: تعد الاحياء التقليدية التي تتكون من تجمعات سكانية ذات أصول ريفية وبالاخص أحياء (12, (بيع الاول ) أو ما يسمى (7 نيسان) و كذلك حي الثام والفاروق، والتي تتمتع بعلاقات اجتماعية تمتاز باختلافها عن بقية الاحياء السكنية الاخرى، إذ تتصف بزيادة اسباب ظاهرة الترييف في مدينة القائم، وذلك كون أغلب سكاها 
تعود لعائلات تعود لعشيرة معينة، حيث يهافظ أهل تلك الاحياء على الروابط والعلاقات العشائرية، كما يؤ كد ذلك الجمدول (3) إذ يشير الى أن (85.7\%) يتمتعون بعلاقات اجتماعية متينة يسودها اللقاء والتواصل فيما بينهم وبشكل عفوي وبلدون مواعييد مسبقه عكس المجتمعات الحضرية المعاصرة(12) في أوقات غير رسمية من اجل تحقيق علاقات اجتماعية يتم من خلالها توطيد أو اصر القرابة، وبوصفه هدفاً يمكن من خحاله الوصول إلى تحقيق التفاعل الاجتماعي وصولاً إلى المجتمع الامثل، فيما أكد ما نسبته (11.4\%) من بحتمع المدينة على صلى وجود علاقة وتماسك اجتماعي بلدرجة متوسط. مدى تأمين الجيران على المتزل: تشير بيانات الجمدول (3) على أن نسبة (43\%) من بحتمع الدراسة يشعرون بالامان بالنسبة لقضية الجوار وما يقارب من (51\%) تكون نسبة الامان للديهم بشكل نسبي وخاصة في الاحياء التي تتمتع بنسبة من التحضر وانخفاض مستويات العلاقات العشائرية فيما بين ساكنيها.

حيث يعد سكان الاحياء القديمة من منطقة الدراسة والتي يتمتع ساكنيها بعلاقات باتت متشعبة من خحلال المصاهرة والقرابة المتولدة من طول المدة الزمنية على بتحاور هؤلاء الناس فضلاً عن علاقة الانتماء العشائري، حتى اهم اصبحوا يشعرون و كأهم بعظهم جزءاً من بعض، مما يولد صورة رائعة من التكافل و التضامن الاجتماعي (13) مبني على القيم العربية وتعاليم الاسلام الحنيف. 3- نشاطات اقتصادية (تربية الحيوانات، الزراعة الحضرية).

يشكل سكان القرى والأرياف الذين استوطنوا المدن جزءاً من قوة العمل للنشاط الزراعي سوء زراعة المحاصيل أو تربية الحيو انات أو تلجين الدواجن(14). و تتجلى هذه الظاهرة بشكل ملحوظ داخل مدينة القائم وهذا مائو كده الجدول (4) و الشكل (2) إذ يبين أن حوالي (57.1\%) من الأسر المدروسة تؤيد محارسة تربية الحيوانات مستغلين الفضاءات ومصادر المياه المتوفرة، فضلاً عن عدم وجود رادع إداري يمنعهم من محارسة هذه المهنة ضمن الحيز الحضري، بحيث يتم إنشاء زرائب المواشي داخل الأحياء السكنية، أما الدواجن فعادة" ما يتم تربيتها على الأسطح، ويؤدي وجود المواشي و الطيور الداجنة إلى انتشار مشاكل بيئية وآفات علديدة بين السكان. وهذا النشاط بالتأكيد له آثار سلبية على ما يحيط همم من بحمعات حضرية التي يعد سكاها في الغالب من الذين يمارسون مهنة التجارة أو الصناعية و ضمن الوظائف الخحكو مية. 
جدول رقم (4) نسب الأسر التي تؤيد تربية الحيوانات داخل المدينة

\begin{tabular}{|c|c|c|}
\hline كل (\%) & نعم (\%) & \\
\hline$\% 42.9$ & $\% 57.1$ & 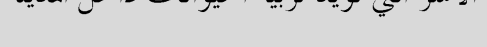 \\
\hline
\end{tabular}

شكل رقم (2) نسب الأسر التي تؤيد تربية الحيوانات داخل المدينة

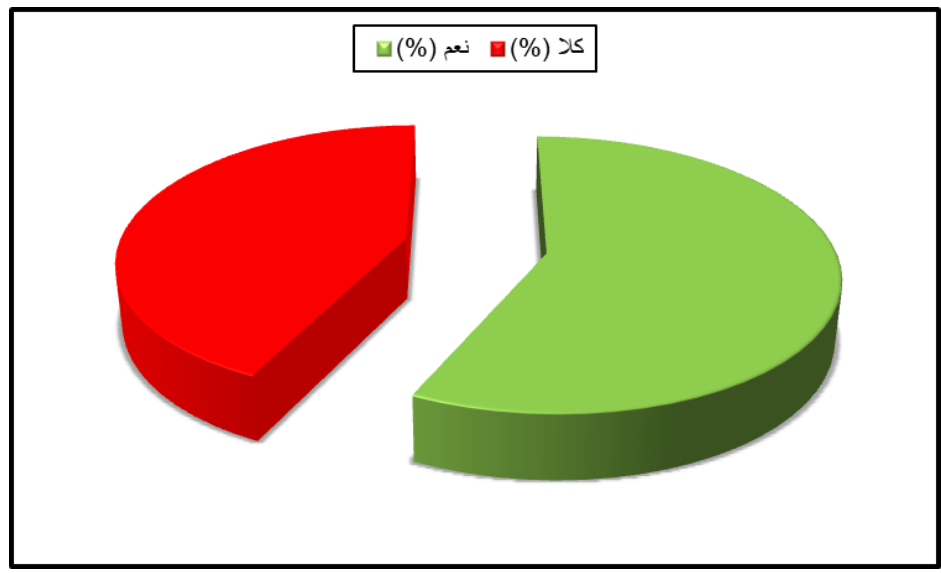

المصدر / بالاعتماد على بيانات جدول (4).

4- ب نغط السلو كيات الريفية:

من مظاهر الترييف التي نلاحظها في المدن وجود بعض السلو كيات والأفعال التي تمارس في الريف بدأت

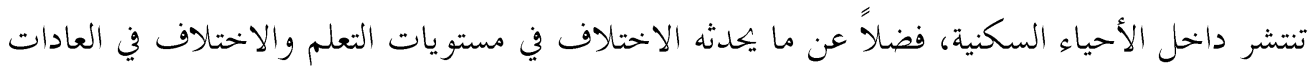
و التقاليد والتباين في مستوى ثقافة المجتمع من وجود بيئة ملائمة لترسيخ بعض العادات والتقاليد داخل

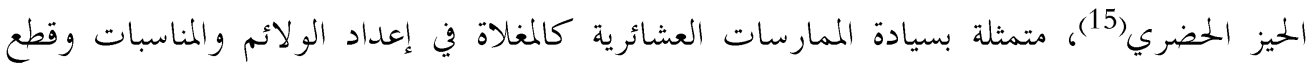

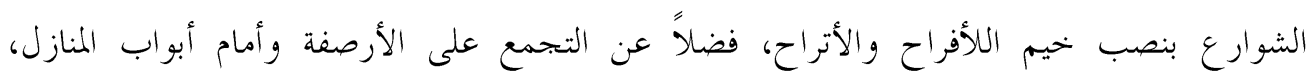

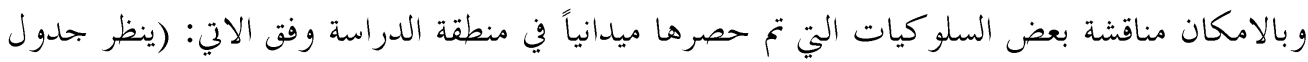

لعب الأطفال مع أبناء الجيران: تعد الأحياء القديمة وذات الطراز التقليدي التي تقع ضمن الحيز

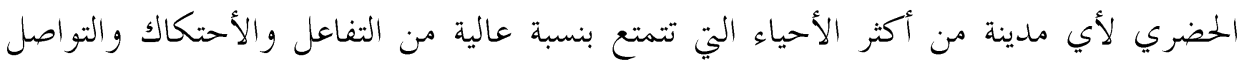

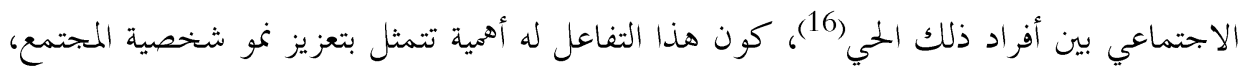

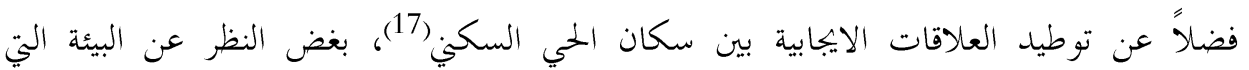
ينحدرون منها وعلى اختلاف اعر اقهم وبيئاقم، والتي تؤدي الى نتيجة حتمية تتمحور حول تعميق 
العلاقات وترسيخ المبادئ الاجتماعية عن طريق زيادة اللقاءات والتزاور والاحتكاك العائلي وعلى مختلف الفئات والأعمار، لذلك يتبين من خلال الدراسة الميدانية لمدينة القائم والمتمثلة بالجدول

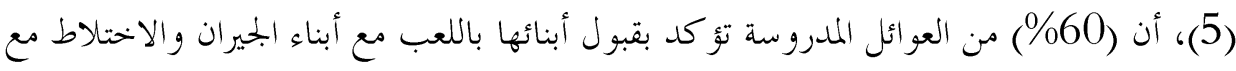

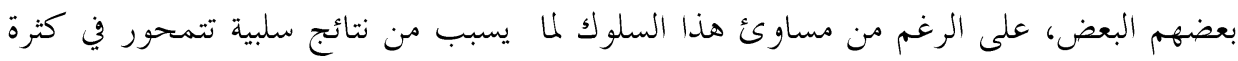
الشجار بين الأبناء ثم سرعان ما ينتقل الى الكبار.

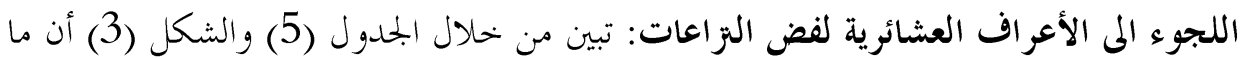

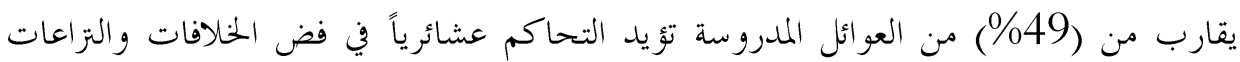
العائلية والمجتمعية، وقد برزت هذه الظاهرة في مدينة القائم وعلى وجه التحديد في الأحياء ذات

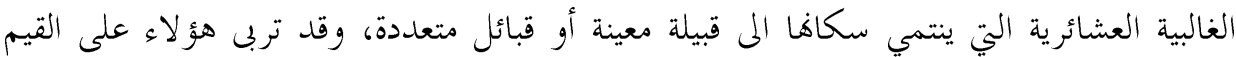
و المبادئ العشائرية ولازال الولاء للعشيرة مقدم على الولاء للمدينة الحضرية، وليس في حساهم الانصياع و التحاكم الى القو اني المعمول بها في المدينة.

جدول رقم (5) أبرز السلو كيات الريفية داخل مدينة القائم

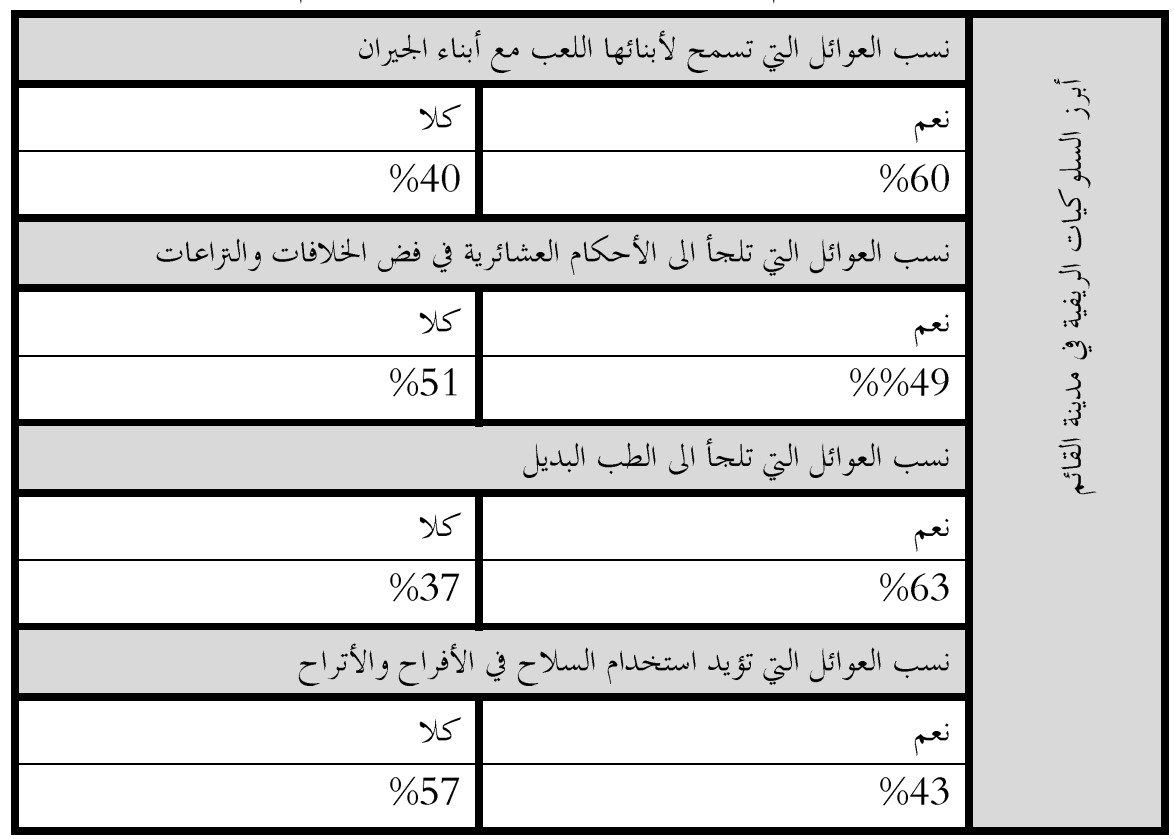


شكل رقم (3) أبرز السلو كيات الريفية داخل مدينة القائم

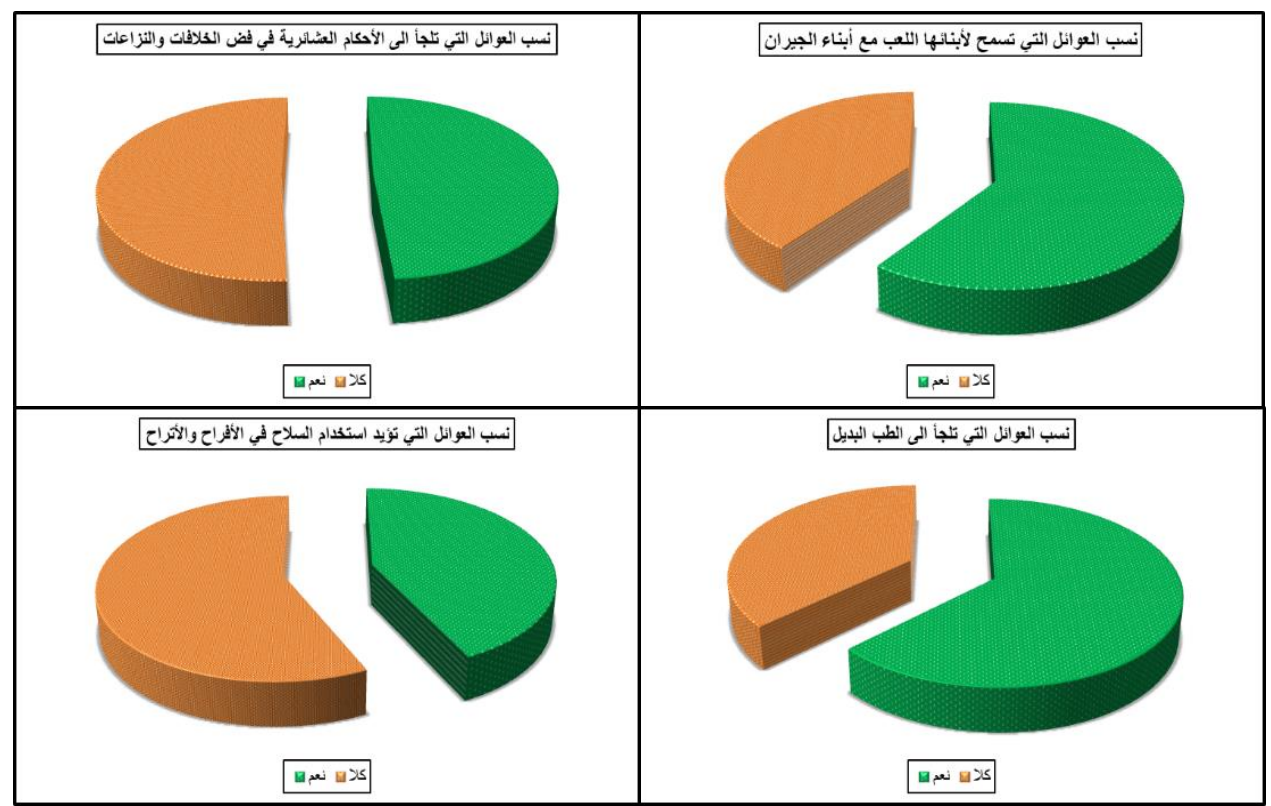

ملىى ممارسة العوائل للطب البديل: والتي بلغت نسبتهم ما يقارب من (63\%) من عدد العو ائل المشمولة بالدراسة، إذ يعتمد في بعض الاحيان على بعض الاجراءات والاساليب التي يقوم هما بعض الاشخاص باستخدام خلطات من الاعشاب في مداواة بعض الأمراض واليت بات بعض من الاطباء الحكوميين ينصحون المرضى بالتداوي عند هؤلاء، الى جانب ذلك لجوء الكثير من الناس للتداوي بالرقية الشرعية وهذا يكون حسب درجة ايمان الفرد، إلا أن مثل هذه الاساليب وفي حال تغافل القانون عنها تستخدم في تنفيذ بعض الأغراض كالسحر و الشعوذة من قبل بعض الجهالاء و المنتفعين. استخدام السلاح بشكل غير قانوني: وهذه الظاهرة من أبرز الظواهر التي تكون متلازمة مع أبناء البوادي وأبناء الريف حيث يكون استخدام السلاح بطريقة غير قانونية ولمتتلف الاسباب والمناسبات،وبدأت تنتقل الى المدن لتكون سبب من أسباب ظهور مشكلة الترييف الحضري، حيث يبين الجلدول (5) أن ما نسبته (43\%) من العوائل المدروسة في مدينة القائم تستخدم السالاح متى شاءت و في مختلف المناسبات. 


\section{5- العادات والاعر اف الريفية:}

تعد مشكلة انتشار العادات والاعر اف الريفية داخل الحيز الحضري وعدم انسجامها مع النسيج الخضري

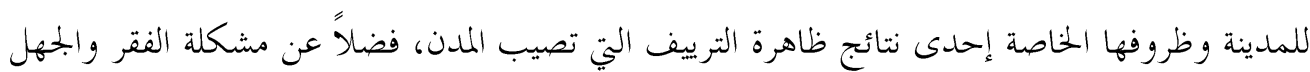
وانخفاض المستوى المعيشي، والذي بدوره يساهم في تدهور النظام الحضري والبيئي للمدينة، ومن هذه العادات التي انتقلت من الريف الى المدينة ما يأتي.

الزواج المبكر للمرأة: باتت هذه الظاهرة تنتشر بشكل غير مسبوق في بحتمعاتنا ولهذه العادات والتقاليد الضرر الكبير الذي يلحق بالمجتمع الحضري. وقد بلغت نسبة الذين

$$
\text { يؤيدون الزواج المبكر ما يقارب من (86\%) من بحتمع الدراسة. }
$$

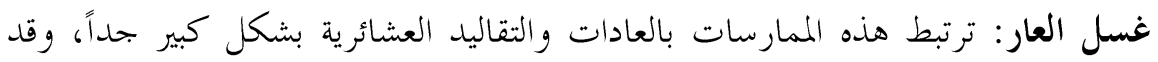

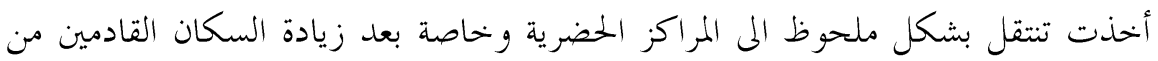

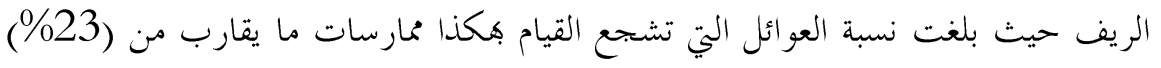
من بحتمع الدراسة وهذه نسبة كبيرة اذا ما قورنت بالمجتمعات المتحضرة سواء في العراق أو أو لونيات العالم العربي المجاور.

بروز العشائرية والحزبية بشكل واضح في تسنم القيادة في المجتمع: ان عدم وضع الرجل

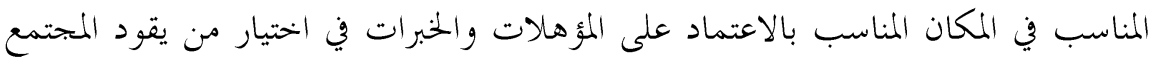
والاقتصار على اختيار الشخص وفق المكانة العشائرية تعد مشكلة بحد ذاتها، لان المؤسسات

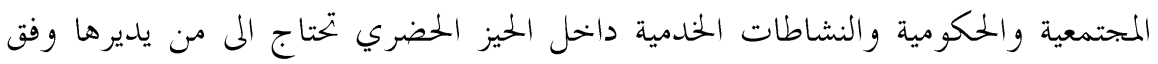

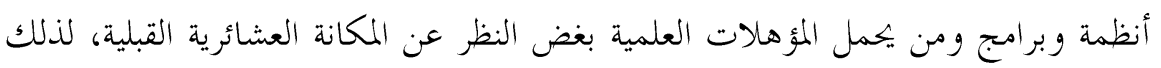

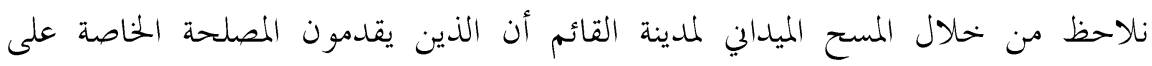
المصلحة العامة بلغ (49\%) من بحمو ع بحتمع العينة.

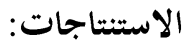

1. ماهمت العلاقات الاجتماعية في ترسيخ ظاهرة عملية التريف الحضري في مدينة القائم، ولهذا فان للروابط والعلاقات الاجتماعية الأثر البارز في اظهار الكثير من سلبيات النسيج الحضري. 2. كان للتوسع المساحي للمدينة بعملية الدمج الحضري دور مهم لبروز هذه الظاهرة.

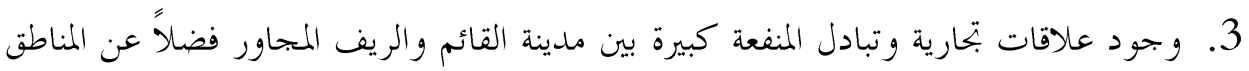
الريفية التابعة لقضائي عنه و راوه. 
1- تقليص الدور المركزي لمدينة القائم من خحلال توفير كل ما يمتاجه السكان من خدمات ادارية و خحمات بحتمعية في المراكز الحضرية كناحية العبيدي و ناحية الرمانة وناحية الكرابلة. 2- ضرورة تنمية المناطق الريفية والعمل على توفير متطلبات السكان من الخلدمات العامة والخدمات الادارية.

3- متابعة وتطور خدمات البنى التحتية والخلدمات العامة والخدمات الترفيهية و نشر ثقافة الشعور بالمسؤولية للى الافراد وضرورة الالتزام بالواجبات السكانية بتاه المدينة.

اسود، فلاح شاكر، الخريطة الادارية لمحافظة الانبار، المؤتمر العلمي الاول لجامعة الانبار، 1990، ص12. المراجع:

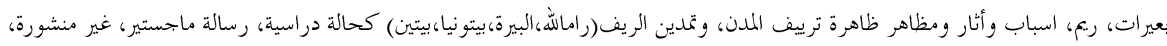
.1

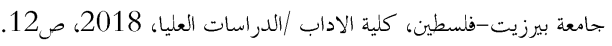
بو مدين، دحماني محمد، اندماج المهاجرين الريفين في الوسط الخضري دراسة ميدانية بمدينة الجلفة، رسالة ماجستير، غير منشورة، جامعة الجزائر

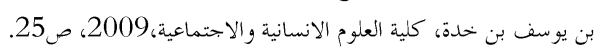
جبير، وئام ياسين، التباين المكاني للتريف الحضري وأثره في البيئة السكنية لمدينة الرمادي، رسالة ماجستير، غير منشورة، كلية التربية للعلوم

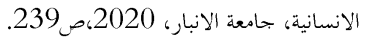
الحديدي، خالد المد عيدان، الترييف الخضري في مدينة الموصل، الاسباب والنتائج، بملة جامعة تكريت، المجلد (20)، العدد (4)،2013، ص 269 6. السعدي، رياض ابراهيم، مكي محمد عزيز، جغرافية السكان، مطبعة جامعة بغداد، 1984، ص134. 7.

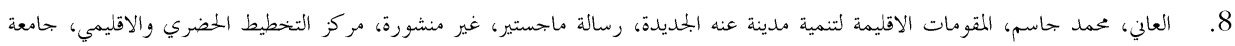

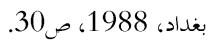
الكربولي،محمود عكاش احمد، مورفولوجية مدينة القائم، رسالة ماجستير، غير منشورة، كلية التربية للعلوم الانسانية، جامعة الانبار، 2011،

$$
\text { . } 63-38
$$

كريدي، هاشم محمد، اثر صناعة الفوسفات على تطور المجتمع الخضري في قضاء القائم، رسالة ماجستير، غير منشورة، كلية التربية، جامعة

محمد دلف أحمد الدليمي، التخطيط للاسكان الخضري بين مبدئي العزل والتداخل السكاني وعلى أساس وحدة الجيرة، بحلة المخطط والتنمية،

(1) ريم بعيرات، اسباب وأثار ومظاهر ظاهرة ترييف المدن، وتمدين الريف(راماللة، البيرة، بيتونيا، بيتين) كحالة دراسية، رسالة ماجستير، غير منشورة، جامعة

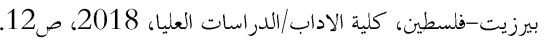


(2) دماني محمد بو مدين، اندماج المهاجرين الريفين في الوسط الحضري دراسة ميدانية بمدينة الجلفة، رسالة ماجستير، غير منشورة، جامعة الخزائر بن يوسف

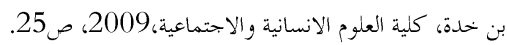

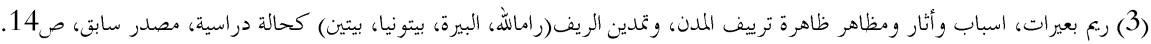

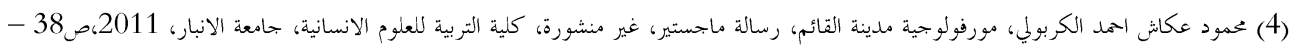

(5) محمد جاسم العاني، المقومات الاقليمة لتنمية مدينة عنه الجديدة، رسالة ماجستير، غير منشورة، مركز التخطيط الحضري والاقليمي، جامعة بغداد،

$$
\text { (30.308 1988 }
$$

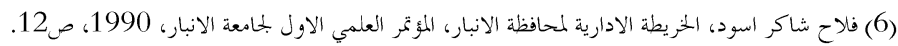

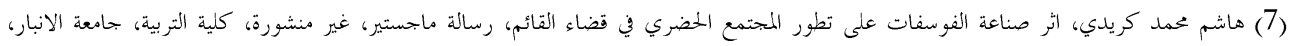

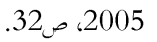

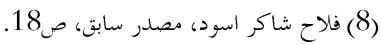

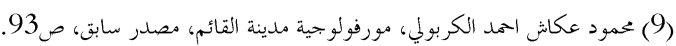
Pn = Po (1+R) N بالاعتماد على المعادلة

$$
\begin{aligned}
& \text { Po }
\end{aligned}
$$

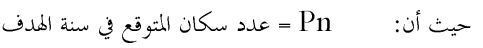

$$
\begin{aligned}
& \text { = R }
\end{aligned}
$$

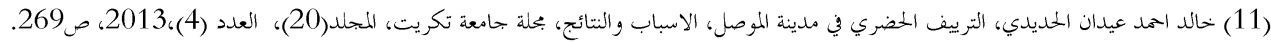

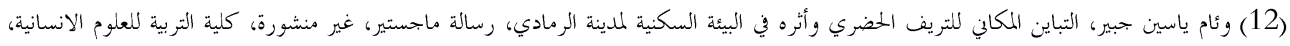

$$
\begin{aligned}
& \text { جامعة الانبار، 2020، 239، } 239 . \\
& \text { (13) المصدر نفسه، ص246. }
\end{aligned}
$$

(14) كامران طاهر سعيد، الترييف الخضري، مدينة السليمانية إنموذجاً، جامعة كوية،ص13، 13، (بكث منشور على شبكة الانترنت).

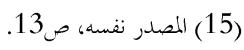

(16) محمد دلف أحمد الدليمي، التخطيط للاسكان الحضري بين مبدئي العزل والتداخل السكاني وعلى أساس وحدة الخيرة، بحلة المخطط والتنمية، جامعة

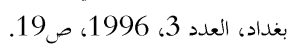

(17) يوسف حامد محمد الملا،، التغير الاجتماعي وضوابط اعداد التصاميم الاساسية للمدن - منطقة الدراسة مدينة الموصل، رسالة ماجستير، غير منشورة،

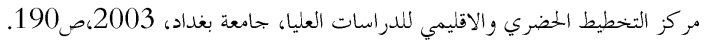

